Research Article

\title{
Prevalence and Association of Obesity with Self-Reported Comorbidity: A Cross-Sectional Study of 1321 Adult Participants in Lasbela, Balochistan
}

\author{
I. Khan, ${ }^{1,2}$ Z. Ul-Haq, ${ }^{1,3}$ A. S. Taj, ${ }^{1}$ A. Z. Iqbal, ${ }^{4}$ S. Basharat, ${ }^{5}$ and B. H. Shah ${ }^{1}$ \\ ${ }^{1}$ Institute of Public Health \& Social Sciences, Khyber Medical University, Peshawar, Pakistan \\ ${ }^{2}$ Institute of Public Health, Quetta, Balochistan, Pakistan \\ ${ }^{3}$ Institute of Health and Wellbeing, University of Glasgow, Glasgow G12 8RZ, UK \\ ${ }^{4}$ Peshawar Institute of Medical Sciences, Peshawar, Pakistan \\ ${ }^{5}$ Health Services Academy, Islamabad, Pakistan \\ Correspondence should be addressed to Z. Ul-Haq; drzia@kmu.edu.pk
}

Received 12 January 2017; Accepted 31 July 2017; Published 12 October 2017

Academic Editor: Malgorzata Bala

Copyright (C) 2017 I. Khan et al. This is an open access article distributed under the Creative Commons Attribution License, which permits unrestricted use, distribution, and reproduction in any medium, provided the original work is properly cited.

\begin{abstract}
Association of fatness with chronic metabolic diseases is a well-established fact, and a high prevalence of risk factors for these disorders has increasingly been reported in the third world. In order to incorporate any preventive strategies for such risk factors into clinical practice, decision-makers require objective evidence about the associated burden of disease. A cross-sectional study of 1321 adults from one of the districts of Balochistan, among the most economically challenged areas of Pakistan, was carried out for the measures of fatness and self-reported comorbidities. Body mass index (BMI), waist circumference (WC), and waist-to-hip ratio (WHR) were measured and demographic information and self-reported comorbidities were documented. The prevalence of obesity was $4.8 \%$ (95\% CI: $[3.8,6.1])$ and $21.7 \%$ (95\% CI: [19.5, 24.0]), as defined by the World Health Organization (WHO) international and Asia/Asia-Pacific BMI cut-offs, respectively. The proportion exhibiting comorbidity increased with increasing levels of fatness in a dose-response relationship ( $p$ value $<.001$ ). An interaction of weight status with gender was observed to produce a significantly $(p=.033)$ higher comorbidity among overweight women (odds ratio $(\mathrm{OR})=6.1[1.2,31.7])$ compared with overweight men $(\mathrm{OR}=$ $1.1[0.48,2.75], p=.762)$.
\end{abstract}

\section{Introduction}

Globally, the prevalence of obesity more than doubled between 1980 and 2014. Around 1.9 billion (39\%) adults, 38\% of men and $40 \%$ of women, have been reported to have weights above the normal range. Of these, over 600 million (13\%) were found to be obese ( $11 \%$ of men and $15 \%$ of women) [1]. This obesity epidemic, previously thought to be a burden of affluent societies, has been noticed to have reached the lowand middle-income countries as a result of the epidemiologic transition [2-4].

Developing countries have been noted to be facing a dual burden of undernutrition and overnutrition simultaneously, exerting substantial strains on the already overburdened health systems [4]. The prevalence of overweight and obesity has increased severalfold in Asia, especially in South Asia [5], over the past few decades, with the extent varying between countries [6], although not very different from that in the United States [7]. Pakistan stands eighth among the 10 countries hosting half of the 693 million obese individuals in the world: USA, China, India, Russia, Brazil, Mexico, Egypt, Pakistan, Indonesia, and Germany [8].

Obesity is a major risk factor for a range of chronic disorders such as cardiovascular diseases (CVD), hypertension, type 2 diabetes mellitus (DM), hypercholesterolemia, osteoarthritis (OA), major depression [9], and certain cancers (CA) [8]. Globally, $23 \%$ of CVD, $44 \%$ of type $2 \mathrm{DM}$, and $7-41 \%$ of certain cancers are attributable to overweight and obesity, with a major share from developing countries [5]. 
Obesity has been found to be associated with at least as much morbidity as poverty, smoking, and alcoholism, despite receiving lesser attention in clinical practice and public health domains [10]. In Asia, there is a general paucity of research on obesity using metrics other than BMI, and even for BMI, the cut-off values used are not Asia-Pacific-specific as recommended by the WHO.

The plight of multiple comorbid states has been reported to afflict up to $50 \%$ of adult populations [11], with the estimates varying from $13 \%$ to $95 \%$ [12]. A palpable lack of research focus regarding the overall burden of this important health problem as well as the balance of inquiry regarding geographic and diagnostic entities has been highlighted, especially for the relatively less disadvantaged tiers of populations in the Eastern Mediterranean region [13].

The aim of this study was to determine the prevalence of obesity and its association with self-reported comorbidity by using different anthropometric measures: BMI (both WHO international and Asian cut-offs), waist circumference (WC), and waist-to-hip ratio (WHR). We also investigated whether the associations varied by gender among a representative sample of adults from the population of the Lasbela District, Balochistan.

\section{Methods}

2.1. Sample Size. Assuming a $15 \%$ prevalence of obesity in Pakistan [14], a sample size of 1225 individuals would estimate the true population proportion of obese persons with a $2 \%$ margin of error at $95 \%$ confidence level. Adding a $10 \%$ nonresponse rate, a sample size of 1347 was targeted.

2.2. Data Source. Data were collected using multistage stratified random sampling [15]. Out of a sampling frame of 30,000 households from 22 union councils treated as strata, a simple random sample of 270 households and 1321 individuals was selected after exclusion of nonresponders, with a number proportionate to the population from each union council. A list of households in each union council was obtained from the local census offices.

2.3. Data Collection. Data for all persons 18 years of age or older, excluding pregnant females, were collected. Faceto-face interviews were conducted by staff specially trained in the measurement process and filling the data collection instrument. The information gathered consisted of demographics (age, gender, education, monthly income, occupation, marital status, and smoking status) and self-reported physician-diagnosed comorbidity (type $2 \mathrm{DM}$, CVD, hypertension, hypercholesterolemia, OA, and CA). Anthropometric measurements including height, weight, $\mathrm{WC}$, and hip circumference (HC) were taken, with standard operating procedures. Each measurement was taken three times in tandem and then the mean was calculated. BMI was calculated by dividing weight in kilograms (measured after removal of shoes and heavy outer clothing using a CAMRY weighing scale) by the square of height in meters (measured without shoes using a nonstretchable tape). WHR was calculated by dividing WC (measured by a nonstretchable tape at the level of the umbilicus) by hip circumference (measured at the widest point using the same tape) [9].

\subsection{Operational Definitions}

2.4.1. Comorbidity. Within the context of this study, comorbidity is defined as a self-report of a doctor's diagnosis or taking medication prescribed by a doctor for one or more of the following conditions: CVD (coronary heart disease or stroke), hypertension, hypercholesterolemia, type $2 \mathrm{DM}$, osteoarthritis, or cancer [9].

\subsubsection{Obesity}

Body mass index (BMI) based international cut-offs: underweight $\left(<18.5 \mathrm{~kg} / \mathrm{m}^{2}\right)$, normal weight (18.5$\left.24.9 \mathrm{~kg} / \mathrm{m}^{2}\right)$, overweight $\left(25.0-29.9 \mathrm{~kg} / \mathrm{m}^{2}\right)$, and obese $\left(\geq 30 \mathrm{~kg} / \mathrm{m}^{2}\right)$.

The World Health Organization (WHO) recommended cut-offs for Asia and Asia-Pacific region: underweight $\left(<18.5 \mathrm{~kg} / \mathrm{m}^{2}\right)$, normal weight (18.5$\left.22.9 \mathrm{~kg} / \mathrm{m}^{2}\right)$, overweight $\left(23.0-24.9 \mathrm{~kg} / \mathrm{m}^{2}\right)$, and obese $\left(\geq 25 \mathrm{~kg} / \mathrm{m}^{2}\right)$ [16].

Waist circumference (WC) based cut-offs: normal weight $(<94 \mathrm{~cm})$, overweight $(94-101.99 \mathrm{~cm})$, and obese $(\geq 102 \mathrm{~cm})$ for men; normal weight $(<80 \mathrm{~cm})$, overweight $(80-87.99 \mathrm{~cm})$, and obese $(\geq 88 \mathrm{~cm})$ for women.

Waist-to-hip ratio (WHR) based cut-offs: normal weight $(<0.90)$, overweight $(0.90-0.99)$, and obese $(\geq 1)$ for men; normal weight $(<0.80)$, overweight $(0.80-0.84)$, and obese $(\geq 0.85)$ for women [17].

2.5. Ethical Considerations. This study was conducted after approval from the Ethical Board of the Khyber Medical University, Peshawar (KMU-EB). Consent was taken from the participants on a consent form written in English and Urdu and after explaining to them the elements of the informed consent, their autonomy, confidentiality, right to withdraw at any time they felt uncomfortable, measurement process, and the whole purpose of the study.

\section{Statistical Analysis}

Chi-square $\left(\chi^{2}\right)$ tests are used for cross-tabulation analyses. Associations among dichotomized anthropometric measures and comorbidity are assessed by means of univariate and multivariate logistic regression models. Odds ratios (OR) with 95\% confidence intervals (CI) are reported and receiver operating characteristic curves presented for these analyses. In the multivariate model, possible confounding factors, that is, gender, age, marital status, education, monthly income, occupation/work status, and smoking status, are adjusted for. Significance of interactions in logistic regression is assessed using Wald's test. Stata version 12.1 (StataCorp, College Station, Texas) has been used to carry out analyses. All tests of statistical significance are two-tailed with an alpha of .05. 


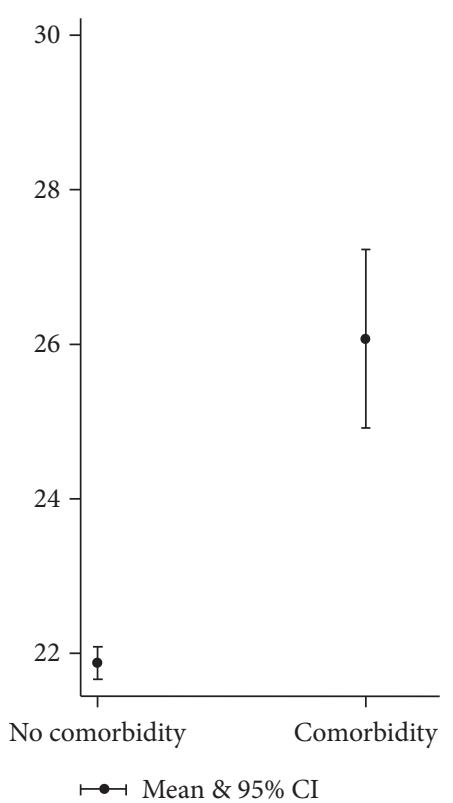

(a) Mean BMI $\left(\mathrm{kg} / \mathrm{m}^{2}\right)$

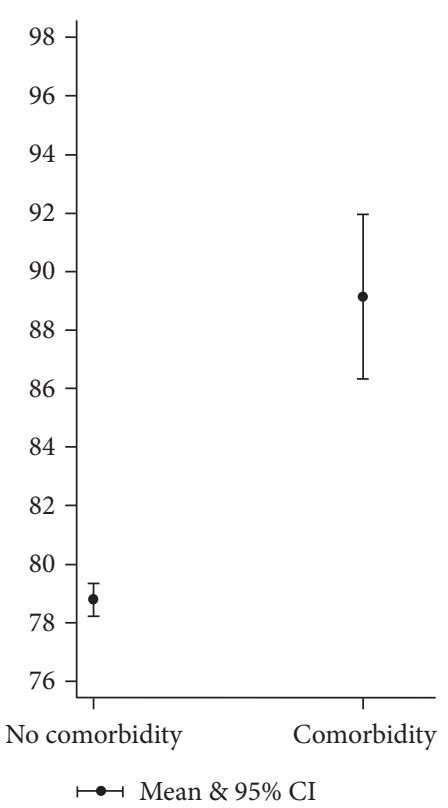

(b) Mean WC (cm)

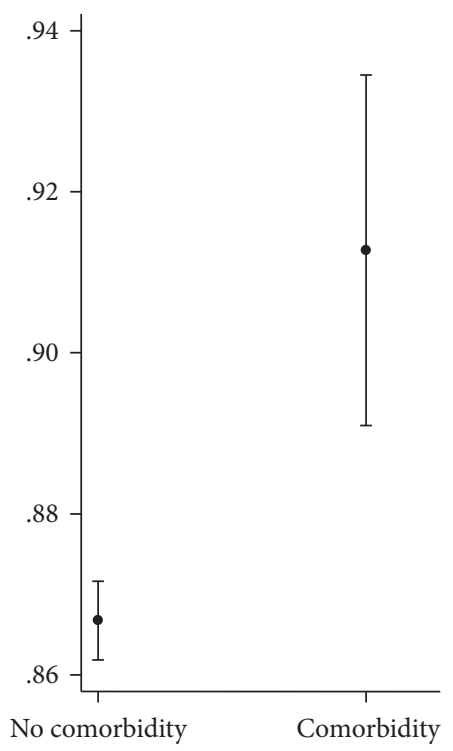

$\mapsto$ Mean \& 95\% CI

(c) Mean WHR

FIGURE 1: Means of anthropometric measurements (overall) with having self-reported comorbidity.

Cohen's $d$ and $r$-squared are reported as measures of effect size for $t$-tests, Cramér's $V$ for chi-square tests, $r$ for two-sample tests of proportions, and OR with CI and area under the receiver operating characteristic curve for logistic regression analyses.

\section{Results}

Complete data were available for 1321 persons. With 26 nonresponders, the response rate was $98 \%$. Compared with the participating family members, the nonresponders did not differ in any significant way.

Of the 1321 participants, 659 (49.89\%) were males. Mean (M) age of the participants was 32.21 years, with a standard deviation (SD) of 12.83 years.

Mean BMI, WC, and WHR were $22.22 \mathrm{~kg} / \mathrm{m}^{2}$ (SD: $\left.4.14 \mathrm{~kg} / \mathrm{m}^{2}\right), 79.61 \mathrm{~cm}$ (SD: $10.86 \mathrm{~cm}$ ), and 0.87 (SD: 0.04), respectively.

Mean BMI, WC, and WHR were all significantly different between those who had one or more comorbid conditions and those without any comorbidity $(t(1319)=-10.3915$, -9.7439 , and -5.0954 ; all $p$ values $<.001 ; d=0.72,0.99$, and $0.52 ; r^{2}=0.08,0.07$, and 0.02 , resp.) (Figure 1).

Among men, mean BMI, WC, and WHR were all significantly different between those who had one or more comorbid conditions and those without any comorbidity $(t(1319)=-4.5358,-7.9175$, and -4.3972 ; all $p$ values < .001; $d=0.69,1.2$, and $0.67 ; r^{2}=0.03,0.09$, and 0.03 , resp.) (Figure 2).

Among women, mean BMI, WC, and WHR were all significantly different between those who had one or more comorbid conditions and those without any comorbidity $(t(1319)=-9.7182,-6.1836$, and $-2.9383 ; p$ values $<.001$,
$<.001$, and $.003 ; d=1.3,0.083$, and $0.4 ; r^{2}=0.12,0.06$, and 0.01 , resp.) (Figure 3).

While WC differed significantly between men $(\mathrm{M}=$ $80.4 \mathrm{~cm}, \mathrm{SD}=11.4 \mathrm{~cm})$ and women $(\mathrm{M}=78.8 \mathrm{~cm}, \mathrm{SD}=$ $10.3 \mathrm{~cm})\left(t(1319)=2.5360, p=.011, d=.14, r^{2}=.005\right)$, BMI and WHR did not show such difference ( $p$ values: .667 and .901, resp.).

The prevalence of obesity was $4.84 \%$ (95\% CI: $[3.8,6.1]$ ) by international cut-offs and $21.73 \%[19.5,24.0]$ on Asian cut-offs of BMI. On WC measurement and WHR measurement, $10.9 \%[9.3,12.7]$ and $44.4 \%[41.7,47.2]$ were obese, respectively. An obese individual was more likely to be $\geq 45$ years of age (two-sample test of proportions: $z=-6.2641, p<$ $.001, r=-0.08)$, married $(z=-3.5053, p<.001, r=-0.1)$, uneducated $(z=2.6437, p=.008, r=0.07)$, and a smoker $(z=-2.9285, p=.003, r=-0.08)$. A person with one or more comorbidities, compared to those without one, was more likely to be female $(z=-4.7976, p<.001, r=-.13)$, forty-five years of age or older $(z=-15.1801, p<.001, r=$ $-.42)$, obese $(z=-8.3415, p<.001, r=-.23)$, uneducated $(z=6.1805, p<.001, r=-.17)$, and current or ex-smoker $(z=-3.0239, p=.0025, r=-.08)$.

Overall, $8.02 \%$ [6.6-9.6\%] of the participants reported themselves as having one or more comorbidities, among whom $43.4 \%[33.8,53.4]$ were men and $56.6 \%[46.6,66.2]$ were women. The difference in proportion of the two genders among those who reported comorbidity was statistically not significant (two-sample test of proportions: $z=-1.9219$, $p=.06, r=-0.13)$.

The prevalence of various comorbid states, with 95\% confidence intervals, was as follows: cardiovascular disease, $1.7 \%[1.0,2.5]$; hypertension, $5.3 \%[4.2,6.6]$; type 2 diabetes mellitus, $2.2 \%[1.5,3.1]$; hypercholesterolemia, 


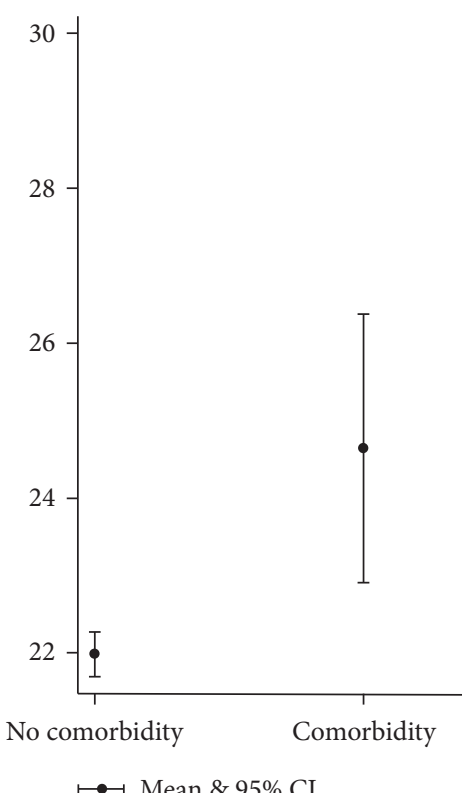

(a) Mean BMI $\left(\mathrm{kg} / \mathrm{m}^{2}\right)$

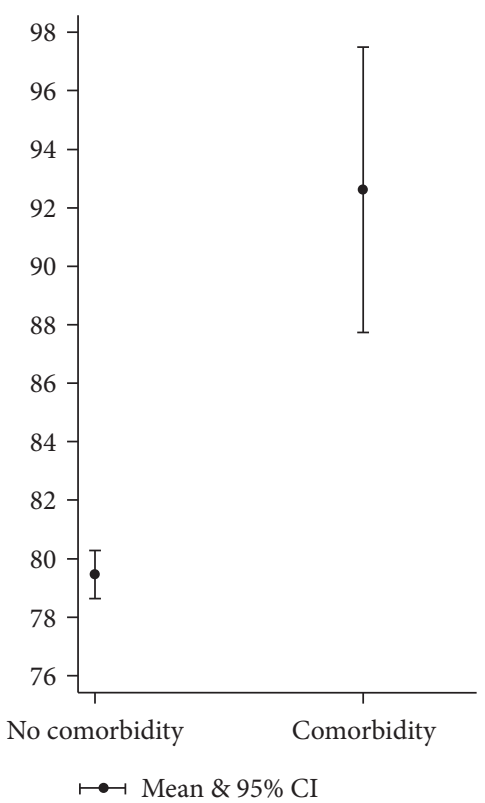

(b) Mean WC $(\mathrm{cm})$

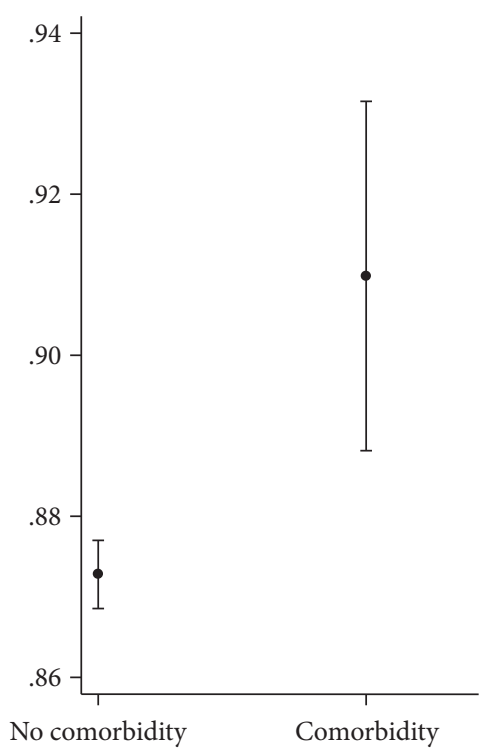

$\mapsto$ Mean \& 95\% CI

(c) Mean WHR

FIGURE 2: Means of anthropometric measurements (men) with having self-reported comorbidity.

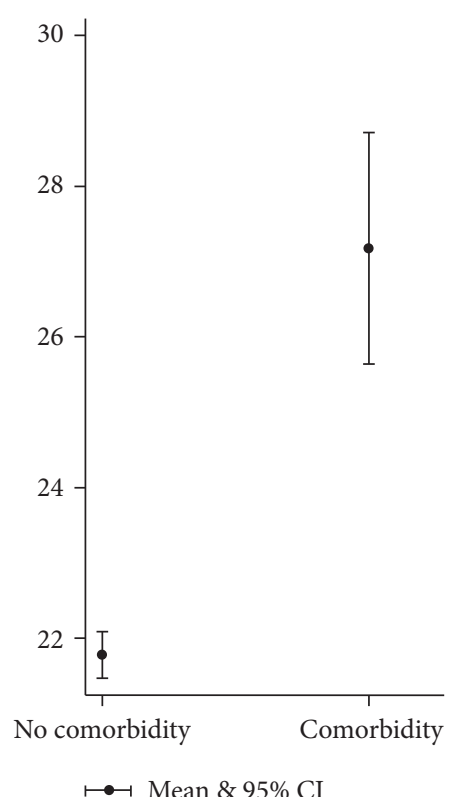

(a) Mean BMI $\left(\mathrm{kg} / \mathrm{m}^{2}\right)$

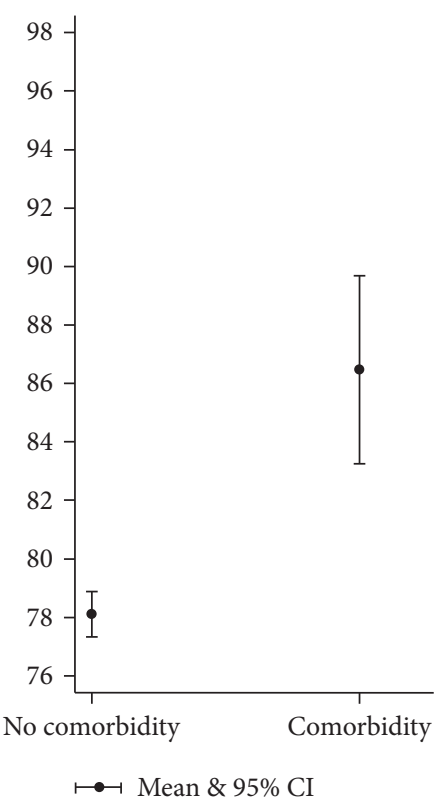

(b) Mean WC $(\mathrm{cm})$

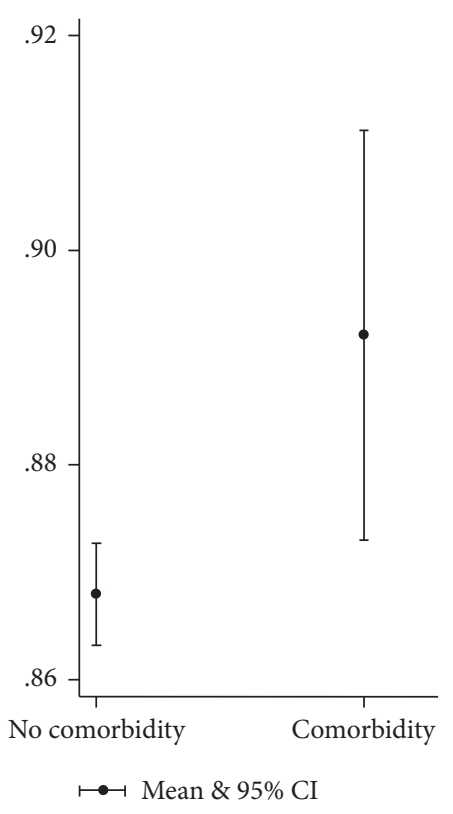

(c) Mean WHR

FIGURE 3: Means of anthropometric measurements (women) with having self-reported comorbidity.

$0.9 \%[0.5,1.6]$; and osteoarthritis, $4.2 \%[3.2,5.4]$. None of the participants reported any malignancy.

All of the following variables were significantly associated with self-reported comorbidity: obesity, using both international and Asian cut-offs for BMI $\left(\chi^{2}(3, N: 1321)=99.16\right.$ and 72.26 , both $p$ values $<.001, V=0.27$ and .23 , resp.), obesity as defined by WC $\left(\chi^{2}(2, N: 1321)=113.70, p<.001\right.$, $V=0.29)$, obesity as defined by WHR $\left(\chi^{2}(2, N: 1321)=\right.$
21.32, $p<.001, V=0.13)$, age $\left(\chi^{2}(3, N: 1321)=255.18\right.$, $p<.001, V=0.44)$, marital status $\left(\chi^{2}(1, N: 1321)=21.48\right.$, $p<.001, V=0.13)$, educational status $\left(\chi^{2}(1, N: 1321)=\right.$ $38.22, p<.001, V=-0.17)$, and smoking status $\left(\chi^{2}(2, N\right.$ : $1321)=9.42, p=.009, V=0.08)($ Table 1$)$.

In overall multiple logistic regression analysis, after adjusting for potential confounders, that is, gender, age, marital status, education, monthly income, occupation/work 
TABLE 1: Characteristics of the participants by self-reported comorbidity.

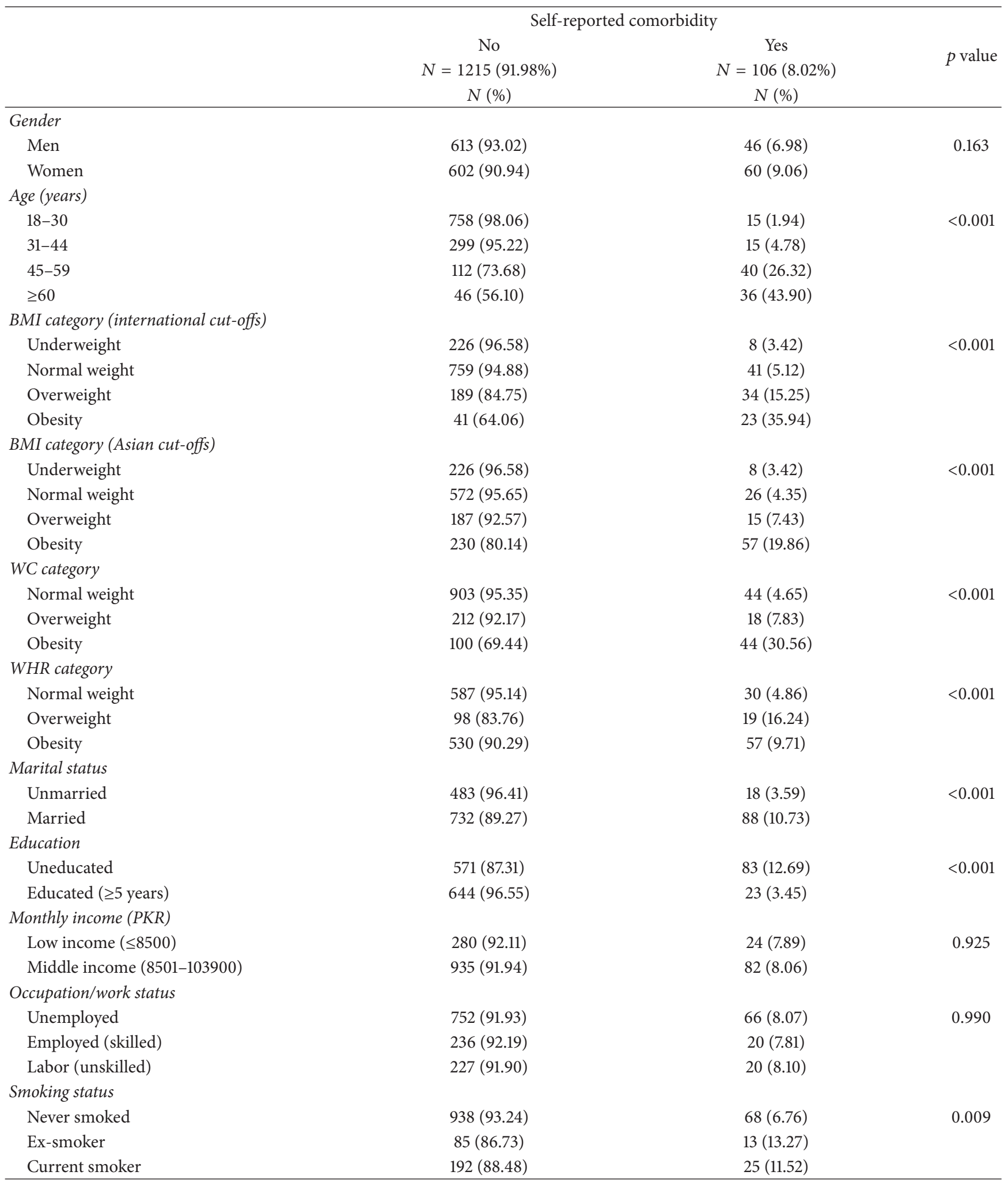

Comorbidity is the presence of one or more of the following conditions: type 2 DM, hypertension, CVD, hypercholesterolemia, OA, and CA. The reported $p$ values are for chi-square tests of independence for categorical data. 
Logistic regression receiver operating characteristic curve Outcome: comorbidity

Covariates: BMI categories, age categories, income categories (Table 1), marital status, education, occupation, and smoking status

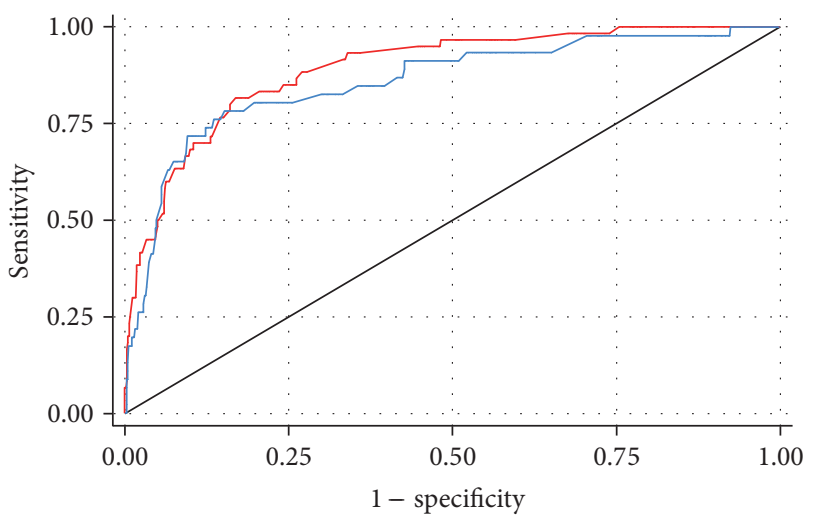

- Females: area under ROC curve $=0.89 ; 95 \%$ CI: $[0.87,0.91]$

— Males: area under ROC curve $=0.86$; $95 \% \mathrm{CI}$ : $[0.83,0.89]$

FIGURE 4: Areas under the ROC curve from logistic regression for males and females.

status, and smoking status, the association between obesity (as defined by international and Asia-specific cut-off values of BMI) and comorbidity was significant (odds ratios (OR) $=5.75[2.84,11.64]$ and $2.87[1.66,4.97]$, resp., both $p$ values $<.001)$. Overweight was significantly associated with comorbidity only as defined by international cut-offs only $(\mathrm{OR}=$ $1.89[1.10,3.26], p=0.021)$.

Association between obesity as defined by waist circumference and comorbidity was significant $(\mathrm{OR}=3.76$ $[2.06,6.85], p<.001)$. However, obesity as defined by waist-to-hip ratio did not show a significant association with comorbidity (OR $=1.72[.63,4.72], p=.292$ ) (Table 2).

In gender-specific multiple logistic regression analysis, the association between obesity and comorbidity for men was significant for international BMI cut-offs ( $\mathrm{OR}=8.49$ [2.50, 28.81], $p=.001$ ) but not for Asian cut-offs (OR = $1.96[.86,4.48], p=.109)$; for women, the association was significant for both cut-offs $(\mathrm{OR}=5.19[2.03,13.26], p=.001$; $\mathrm{OR}=3.73[1.68,8.29], p=.001$, resp.) (Figure 4).

The international cut-offs defined overweight was significantly associated with the outcome of comorbidity for women only $(\mathrm{OR}=2.64[1.23,5.67], p=.013)$, an association not observed in men or with the Asian cut-offs of BMI for women.

Obesity as defined by waist circumference was significantly associated with comorbidity for men as well as women $(\mathrm{OR}=6.38[2.24,18.19], p=0.001 ; \mathrm{OR}=3.38[1.49,7.64]$, $p=.004$, resp.). As defined by waist-to-hip ratio, obesity did not show significant association for either sex.

The overweight category by both cut-offs for BMI showed an interaction with gender to produce significant association
(OR: $6.05[1.16,31.74], p=.033$ ) with the outcome of comorbidity for women but not men $(\mathrm{OR}=1.14456[0.48,2.75]$, $p=.762)$.

There was a significant linear trend of increasing comorbidities with progressively increasing weight categories, both by international and by Asia/Asia-Pacific cut-offs (Cuzick's tests for linear trend: $z=8.83$ and 7.73, resp., $p$ values $<.001)$.

\section{Discussion}

Worldwide, obesity has been reported to incur a twofold increase in the risk of diabetes, hypertension, heart failure, ischemic stroke, ischemic heart disease, and osteoarthritis [18-22]. Our study has found a significant dose-response relationship between increasing comorbidities and increasing weight.

The association has important implications for public health planning and management as health effects of obesity at individual and community levels manifest themselves through these comorbid states, which we have shown to be increasing in direct proportion with increasing weight.

Thirty-seven percent [34.4,39.7] of the participants in this study were either overweight (15.3\% [13.4, 17.3]) or obese $(21.7 \%[19.5,24.0])$, according to the recommended BMI cut-offs for Asian populations. Twenty percent $[15.40,24.95]$ of the obese individuals had one or more comorbid conditions.

Our results show a significantly higher prevalence of obesity among those who were 45 years of age or older, married, uneducated, and smokers. Such associations have been reported by various studies across the world including Asia and South Asia [23].

We have found the prevalence of obesity to be $21.7 \%[19.5,24.0]$ and that of underweight to be $17.8 \%[15.7,19.9]$, highlighting the simultaneous burden of the two extremes [4]. The prevalence of underweight that we found is higher than that reported in Pakistan previously $(12.3 \%)$ [14], probably a reflection of the locale specific economic realities.

Our finding of a significant association of obesity with comorbidities has been reported previously [24] but the levels of different anthropometric measurements at which the participants reported comorbidity in our study were lesser compared to those reported in USA and Europe, probably because Asians are known to carry greater body fat content for a given BMI [25].

This study has shown that the association between BMI (international cut-offs) and self-reported comorbidity differs by the gender; while only obese, not overweight, men were significantly more likely to report comorbidity, both overweight and obese women showed such association. Overweight men, compared with overweight women, have been found to report relatively better quality of life, better psychological health, and more happiness [26-28].

5.1. Strengths and Limitations of the Study. The sampling technique for this study was robust enough to ensure representativeness of the sample and external validity. Different anthropometric measures of obesity as well as various cut-off 


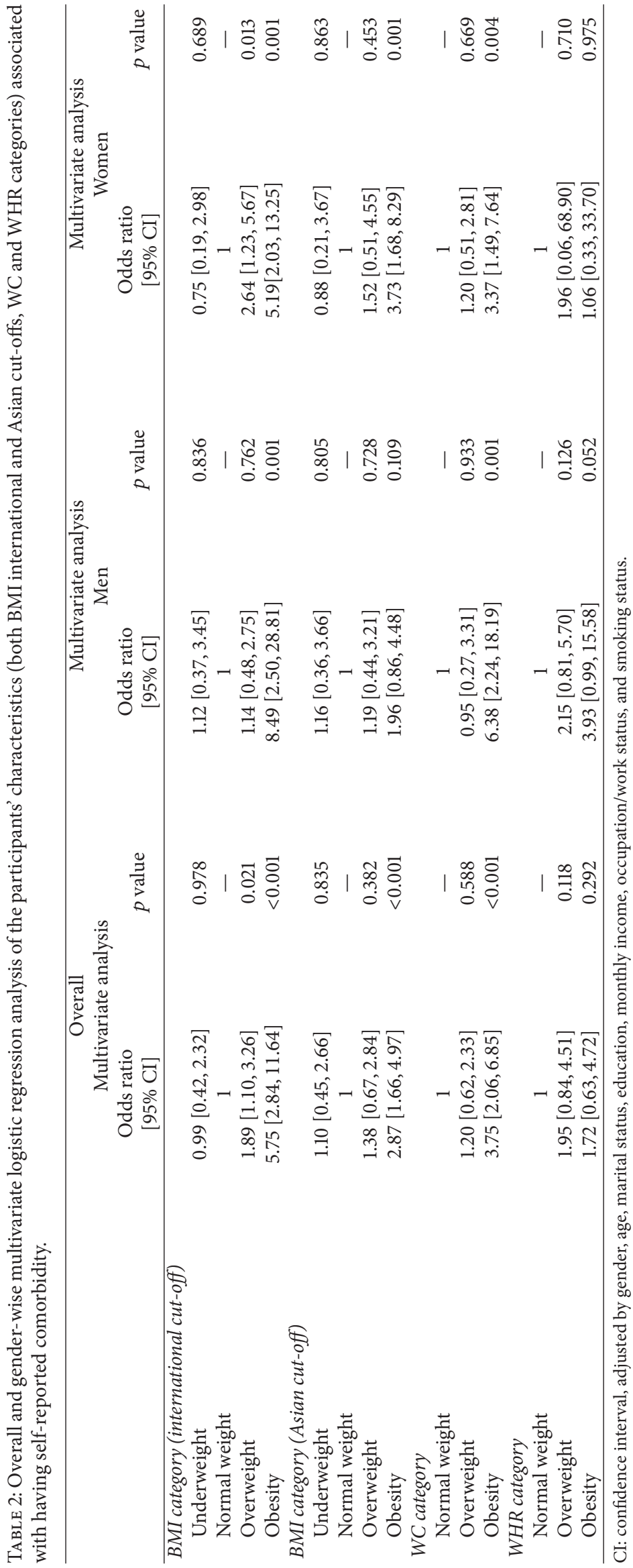


values were used to provide a broader range of assessment for measures of fatness. Anthropometric measurements were done by trained staff rather than relying on self-reported obesity.

Other than being subject to various biases known to beset cross-sectional studies, causality cannot be inferred from the reported associations from this study.

\section{Conclusion}

Comorbidities increase with increasing weight in a doseresponse relationship. With the changing social structure and lifestyles in the area, the problem can only get worse with time if not addressed by healthcare planners.

\section{Recommendations}

In order to reduce the healthcare costs, effective preventive strategies have to be put in place at various tiers of healthcare delivery systems.

Additional research with longitudinal design is needed to define the temporal characteristics of association between obesity and its associated comorbidities.

\section{Conflicts of Interest}

The authors declare that they have no conflicts of interest.

\section{References}

[1] World Health Organization, "Controlling the global obesity epidemic: the challenge," Nutrition, WHO, 2008, http://www.who .int/nutrition/topics/obesity/en/.

[2] A. Boutayeb and S. Boutayeb, "The burden of non communicable diseases in developing countries," International Journal for Equity in Health, vol. 4, 2005.

[3] G. A. Stevens, G. M. Singh, and Y. Lu, "National, regional, and global trends in adult overweight and obesity prevalences," Population Health Metrics, vol. 10, article 22, 2012.

[4] R. F. Florentino, "The burden of obesity in Asia: Challenges in assessment, prevention and management," Asia Pacific Journal of Clinical Nutrition, vol. 11, no. s8, pp. S676-S680, 2002.

[5] "Don't get the idea that all Asian populations are the same," in Proceedings of the World Congress of Europian Society of Cardiology, B. JP, Ed., Barcelona, Spain2006, 2006.

[6] A. M. Prentice, "The emerging epidemic of obesity in developing countries," International Journal of Epidemiology, vol. 35, no. 1, pp. 93-99, 2006.

[7] K. H. Yoon, J. H. Lee, J. W. Kim et al., "Epidemic obesity and type 2 diabetes in Asia," The Lancet, vol. 368, no. 9548, pp. 1681-1688, 2006.

[8] M. Ng, T. Fleming, M. Robinson, and et al, "Global, regional, and national prevalence of overweight and obesity in children and adults during 1980-2013: a systematic analysis for the Global Burden of Disease Study 2013," The Lancet, vol. 384, no. 9945, pp. 766-781, 2014.

[9] Z. Ul-Haq, D. J. Smith, B. I. Nicholl et al., "Gender differences in the association between adiposity and probable major depression: A cross-sectional study of 140,564 UK Biobank participants," BMC Psychiatry, vol. 14, no. 1, article no. 153, 2014.
[10] R. Sturm and K. B. Wells, "Does obesity contribute as much to morbidity as poverty or smoking?" Public Health, vol. 115, no. 3, pp. 229-235, 2001.

[11] C. Violán, Q. Foguet-Boreu, A. Roso-Llorach et al., "Burden of multimorbidity, socioeconomic status and use of health services across stages of life in urban areas: A Cross-Sectional Study," BMC Public Health, vol. 14, no. 1, article 530, 2014.

[12] C. Violan, Q. Foguet-Boreu, G. Flores-Mateo et al., "Prevalence, determinants and patterns of multimorbidity in primary care: a systematic review of observational studies," PLOS ONE, vol. 9, no. 7, Article ID e102149, 2014.

[13] A. Boutayeb, S. Boutayeb, and W. Boutayeb, "Multi-morbidity of non communicable diseases and equity in WHO Eastern Mediterranean countries," International Journal for Equity in Health, vol. 12, no. 1, article no. 60, 2013.

[14] S. Nishtar, Health Indicators of Pakistan -Gateway Paper II, Heartfile, Pakistan, 2007.

[15] M. Abbas, P. I. Paracha, S. Khan, Z. Iqbal, and M. Iqbal, "Sociodemographic and dietary determinants of overweight and obesity in male pakistani adults," European Scientific Journal, vol. 9, no. 33, 2013.

[16] Organization World Health, "International association for the study of obesity, international obesity task force," in The AsiaPacific perspective: redefining obesity and its treatment Sydney: Health Communications, pp. 15-21, 2000.

[17] WH. Organization, Obesity, preventing and managing the global epidemic, World Health Organization, preventing and managing the global epidemic, 2000.

[18] G. A. Colditz, W. C. Willett, A. Rotnitzky, and J. E. Manson, "Weight gain as a risk factor for clinical diabetes mellitus in women," Annals of Internal Medicine, vol. 122, no. 7, pp. 481-486, 1995.

[19] M. Grotle, K. B. Hagen, B. Natvig, F. A. Dahl, and T. K. Kvien, "Obesity and osteoarthritis in knee, hip and/or hand: an epidemiological study in the general population with 10 years follow-up," BMC Musculoskeletal Disorders, vol. 9, article 132, 2008.

[20] S. Kenchaiah, J. C. Evans, D. Levy et al., "Obesity and the risk of heart failure," The New England Journal of Medicine, vol. 347, no. 5, pp. 305-313, 2002.

[21] T. Kurth, J. M. Gaziano, K. Berger et al., "Body mass index and the risk of stroke in men," Archives of Internal Medicine, vol. 162, no. 22, pp. 2557-2562, 2002.

[22] L. Niskanen, D. E. Laaksonen, K. Nyyssönen et al., "Inflammation, abdominal obesity, and smoking as predictors of hypertension," Hypertension, vol. 44, no. 6, pp. 859-865, 2004.

[23] C. D. Mathers and D. Loncar, "Projections of global mortality and burden of disease from 2002 to 2030," PLoS Medicine, vol. 3, no. 11, article e442, 2006.

[24] A. Must, J. Spadano, E. H. Coakley, A. E. Field, G. Colditz, and W. H. Dietz, "The disease burden associated with overweight and obesity," The Journal of the American Medical Association, vol. 282, no. 16, pp. 1523-1529, 1999.

[25] A. Misra and L. Khurana, "Obesity-related non-communicable diseases: South Asians vs White Caucasians," International Journal of Obesity, vol. 35, no. 2, pp. 167-187, 2011.

[26] Z. Ul-Haq, D. F. MacKay, E. Fenwick, and J. P. Pell, "Impact of metabolic comorbidity on the association between body mass index and health-related quality of life: A Scotland-wide crosssectional study of 5,608 participants," BMC Public Health, vol. 12, no. 1, article no. 143, 2012. 
[27] Z. Ul-Haq, D. F. MacKay, E. Fenwick, and J. P. Pell, "Association between body mass index and mental health among Scottish adult population: A cross-sectional study of 37272 participants," Psychological Medicine, vol. 44, no. 10, pp. 2231-2240, 2014.

[28] Z. Ul-Haq, D. F. Mackay, D. Martin et al., "Heaviness, health and happiness: A cross-sectional study of 163066 UK biobank participants," Journal of Epidemiology and Community Health, vol. 68, no. 4, pp. 340-348, 2014. 


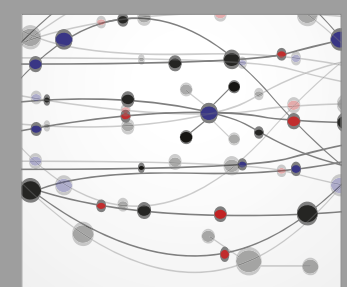

The Scientific World Journal
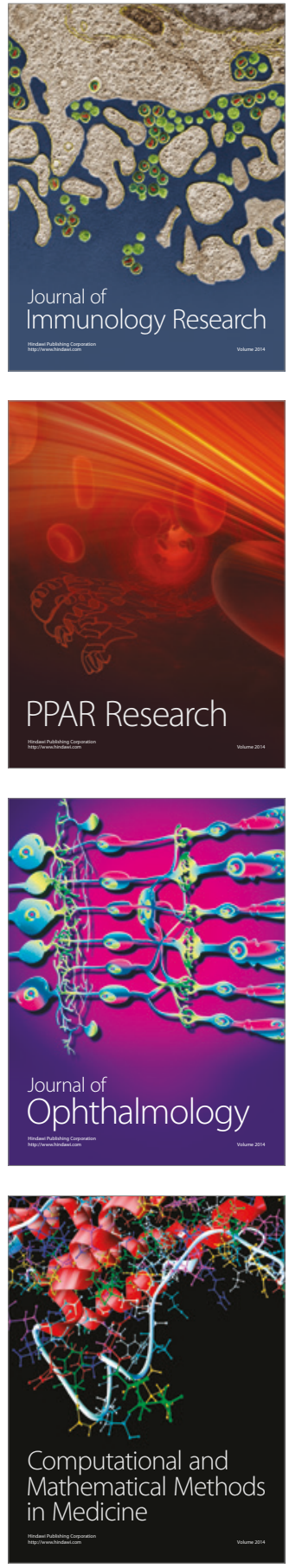

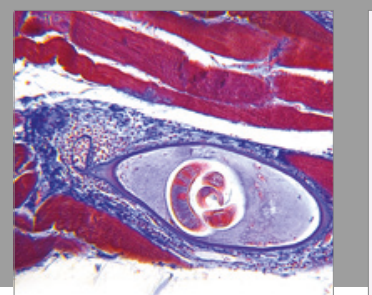

Gastroenterology Research and Practice
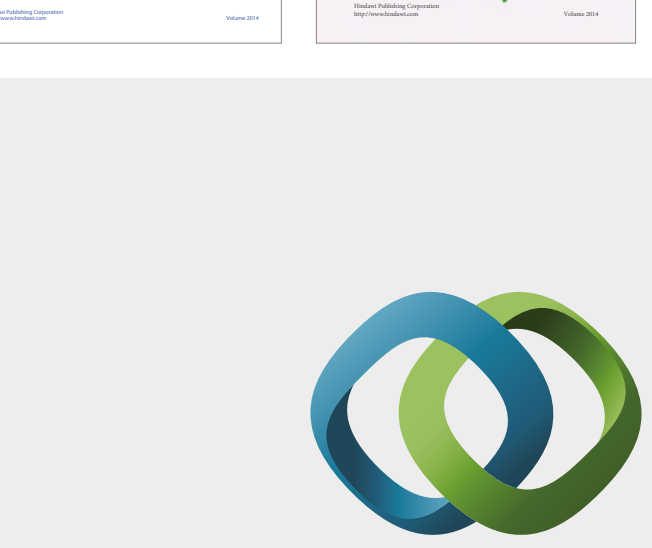

\section{Hindawi}

Submit your manuscripts at

https://www.hindawi.com
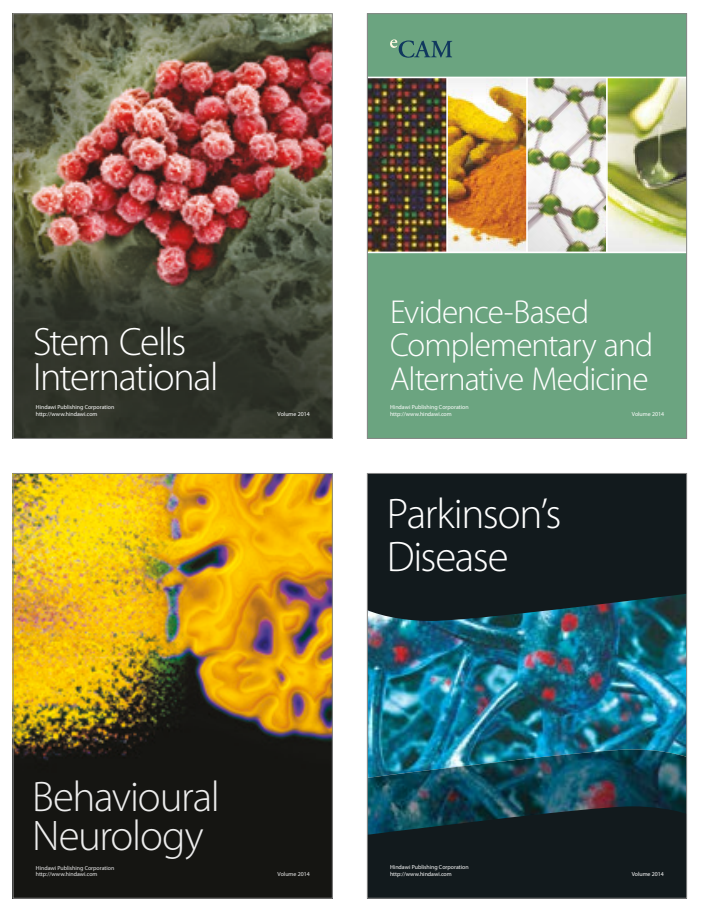
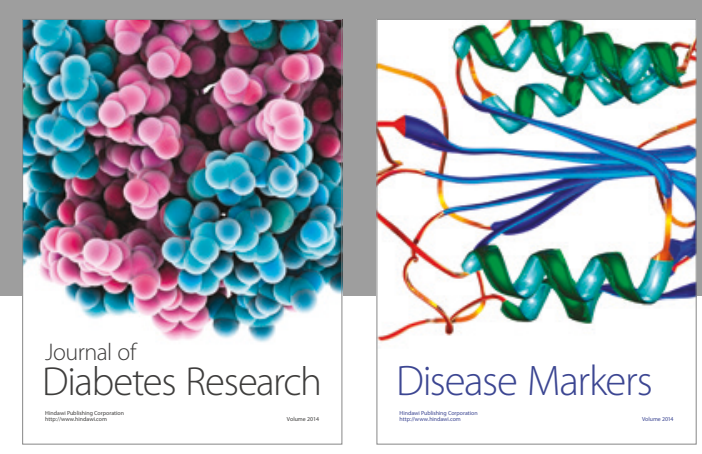

Disease Markers
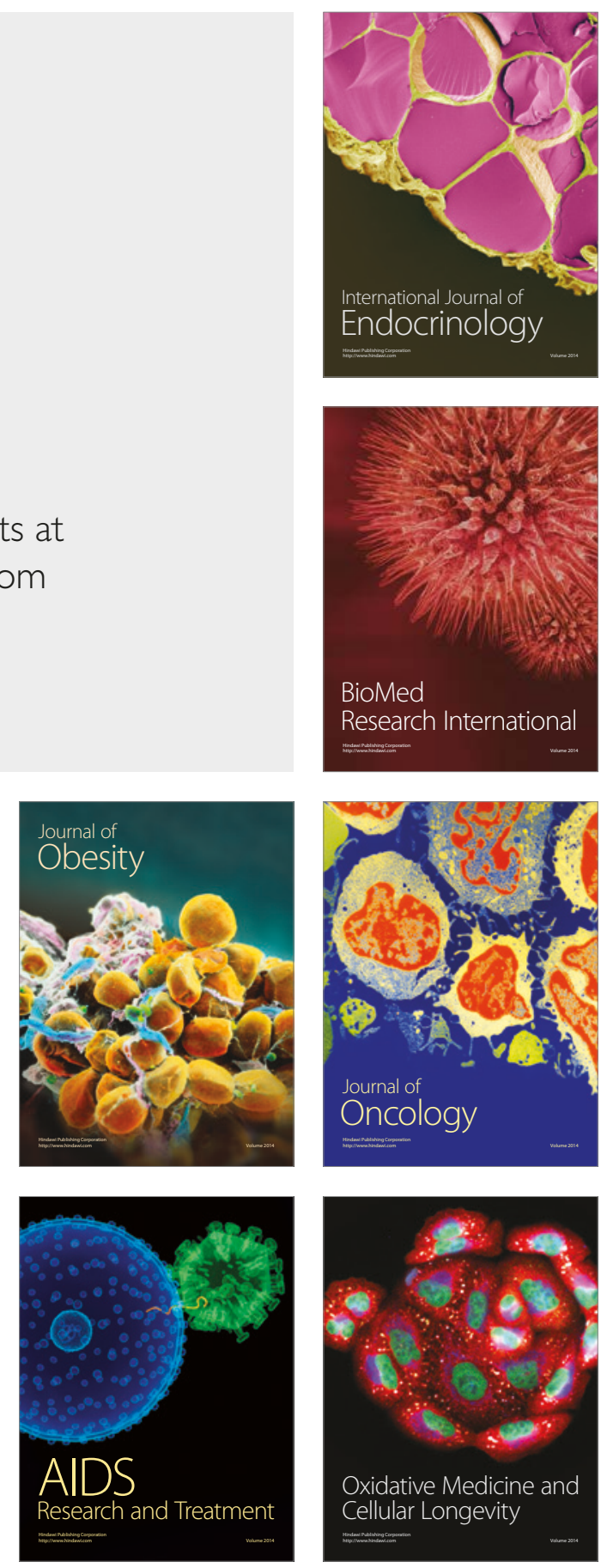